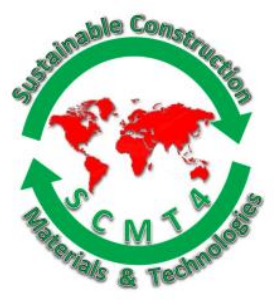

SCMT4

Las Vegas, USA, August 7-11, 2016

\title{
In-Situ Production of Nano/Micro Particles in Fresh Concrete
}

\author{
Jialai Wang*1a, and Xin Qian ${ }^{1 b}$ \\ ${ }^{1}$ Department of Civil, Construction, and Environmental Engineering, The University of Alabama,

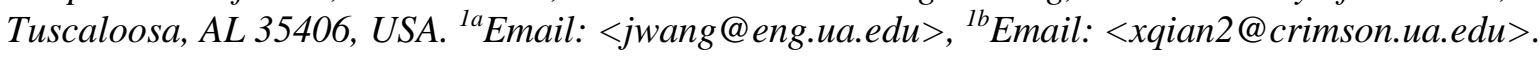

\begin{abstract}
This study proposes a novel method to in-situ produce nanoparticles in fresh concrete using carbon dioxide gas. The new method can significantly enhance the sustainability of concrete through permanently storing carbon dioxide in concrete and increasing the performance of concrete. By using this method, calcium carbonate nanoparticles coated with a thin layer of silica can be in-situ produced in fresh concrete, which can not only serves as ideal nucleating sites for the hydration products of ordinary Portland cement, but also densifies the microstructure of the concrete. Synergistic effects between $\mathrm{CO} 2$ and cementitious material are also triggered by this method: 1) calcium carbonate produced by this method transforms from amorphous or metastable phase to stable phase so that calcium carbonate also functions as binding phase in concrete; and 2) calcium carbonate produced by this method changes the mineralogy of the hydrated cement to produce larger volume of hydration minerals and thereby to reduce porosity of the concrete or harder crystal to strengthen the concrete. Experimental studies show strength of concrete can be significantly increased by this method.
\end{abstract}

\section{INTRODUCTION}

Concrete with OPC as the binder is the most widely used construction material. The global use of concrete is second only to water, accounting for $70 \%$ of all building and construction materials. Although OPC has many advantages such as ease of application and availability of raw materials around the world, the production of OPC releases a large amount of greenhouse gases. Cement production in the U.S. accounts for up to $7 \%$ of the nation's total $\mathrm{CO}_{2}$ emission.

To combat global climate change, the carbon footprint of OPC-based concrete should be reduced. To this end, the amount of OPC used in concrete should be reduced since OPC is the major contributor to the carbon footprint of concrete. This can be realized through partially replacing OPC with minerals. Ground limestone (mainly consisting of calcite $\left(\mathrm{CaCO}_{3}\right)$ ) is one of such minerals because of its limited reactivity with the aluminate phases of OPC (Lothenboch et al. 2008). Thermodynamic simulation and experimental studies show that the $\mathrm{CaCO}_{3}$ can alter the hydration products and stabilize ettringite, leading to an increase of the total volume of the hydrate phase and a reduction of porosity in hardened concrete. Therefore, limited replacement (less than 10\%) of OPC by limestone has little effect on the short and long term performance of concrete. 
Because most of supplementary cementitious materials (SCMs) have aluminate phases which can react with limestone powders, a ternary cement in which blended SCMs and limestone powder are used to partially replace OPC (De Weerdt et al. 2011) has shown great potential. This ternary cement not only has the positive effects of both the reactive and non-reactive mineral powders on concrete, but also takes full advantage of the synergistic effects induced by the limited reaction between the limestone powders and aluminate phase in reactive SCMs. Extensive studies have shown that the ternary cement outperforms the one using individual SCMs (De Weerdt et al. 2011). However, the use of limestone powder is limited to low replacement levels. At higher replacement levels (more than $10-15 \%$ of OPC), most of the limestone is non-reactive and the strength of concrete is reduced due to the dilution effect of the limestone powder (Cheung et al. 2011).

Inspired by the synergistic effect between limestone powder and SCMs, we propose to use $\mathrm{CO}_{2}$ as an admixture for concrete. To implement this idea, a new manufacturing method, pre-carbonation technology, is proposed. This new technology not only enjoys all benefits of the existing technology using limestone powders, but also triggers some new mechanisms which can significantly improve the performance of concrete in an economical way.

\section{WORKING PRINCIPLE}

Since $\mathrm{CO}_{2}$ is in the gas phase in ambient environments, it cannot be directly mixed with other ingredients to make concrete products. However, absorbents can be used to absorb $\mathrm{CO}_{2}$ first, and then mixed with other ingredients to make concrete. Since the cementitious materials used in the concrete - both OPC and some SCMs such as high calcium fly ash, blast furnace slag, cement kiln dust - are rich in calcium, $\mathrm{CO}_{2}$ can be absorbed by these materials through reaction with calcium to produce a mix of calcium carbonate/bicarbonate. Therefore, these calcium-rich cementitious materials serve perfectly as $\mathrm{CO}_{2}$ absorbents and no extra absorbent is needed. If low or non-calcium minerals are used, slaked lime should be added as the absorbent. To implement this pre-carbonation method, the mineral to be used in concrete will be carbonated before mixing with other ingredients of the concrete, as shown in figure 1.

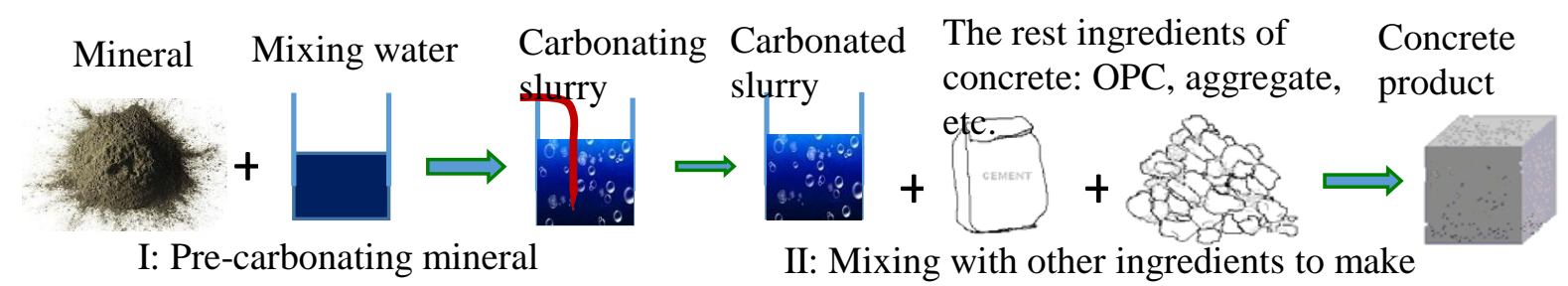

\section{Figure 1. Manufacturing concrete through the pre-carbonation method.}

A simple way to carbonate the mineral with calcium is shown in figure 1 . The mineral with calcium will be mixed with mixing water to form slurry. Then, $\mathrm{CO}_{2}$ is bubbled into this slurry to carbonate the mineral. This method is easy to implement in laboratory for small scale manufacturing of concrete. It may be not practical to pre-carbonate large amount of minerals. In that case, a large-scale precarbonation method used by Kachinski (1983) to carbonate cement kiln dust can be used.

It is well known that adding ground limestone can slightly accelerate the hydration of OPC due to the additional surface area provided by limestone powder for the nucleation and growth of the hydration products of OPC (Pera et al. 1999). The hydration rate of OPC can be significantly increased if limestone nanoparticles are used (Sato and Beaudoin 2010). However, it is difficult to disperse nanoparticles into concrete because of their small size. If the pre-carbonation method is used, $\mathrm{CO}_{2}$ gas is first dissolved in water forming carbonic acid (equation (1)). Then carbonic acid dissociates to 
$\mathrm{H}^{+}$and $\mathrm{CO}_{3}{ }^{2-}$ (equation (2)). With the help of $\mathrm{H}^{+}$ions, $\mathrm{Ca}^{2+}$ in the slaked lime or SCMs are released, which meet with $\mathrm{CO}_{3}{ }^{2-}$ to form calcium carbonate precipitants, which usually are particles in micrometers, as shown in equation (3). If more $\mathrm{CO}_{2}$ is bubbled into the slurry, some of calcium carbonate will be dissolved to form calcium bicarbonate, which has much higher solubility in water, as shown in equation (4).

$$
\begin{aligned}
\mathrm{CO}_{2(a q)}+\mathrm{H}_{2} \mathrm{O} \leftrightarrow \mathrm{H}_{2} \mathrm{CO}_{3} \\
\mathrm{H}_{2} \mathrm{CO}_{3} \leftrightarrow \mathrm{H}^{+}+\mathrm{HCO}_{3}^{-}, \mathrm{HCO}_{3}^{-} \leftrightarrow \mathrm{H}^{+}+\mathrm{CO}_{3}^{2-} \\
\mathrm{Ca}_{(a q)}^{2+}+\mathrm{CO}_{3(a q)}^{2-} \rightarrow \mathrm{CaCO}_{3(s)} \\
\mathrm{CaCO}_{3(s)}+\mathrm{H}_{2} \mathrm{O}+\mathrm{CO}_{2(a q)} \leftrightarrow \mathrm{Ca}_{(a q)}^{2+}+\mathrm{HCO}_{3}^{-}
\end{aligned}
$$

Therefore, after pre-carbonation, the slurry of slaked lime or calcium-rich SCM is rich in $\mathrm{Ca}^{2+}, \mathrm{HCO}_{3}{ }^{-}$ , and small portion of $\mathrm{CO}_{3}{ }^{2+}$, as shown in figure 2(a). After mixing with $\mathrm{OPC}, \mathrm{Ca}(\mathrm{OH})_{2}$ is quickly released into water and reacts with $\mathrm{HCO}_{3}{ }^{-}$to produce calcium carbonate precipitants as given by equation (5)

$$
\mathrm{Ca}(\mathrm{OH})_{2}+\mathrm{HCO}_{3}^{-} \rightarrow \mathrm{CaCO}_{3} \downarrow+\mathrm{H}_{2} \mathrm{O}
$$

Growing calcium carbonate nanoparticles produced in equation (5) in alkaline solution of concrete generates $\mathrm{pH}$ gradientes over their surfaces due to dissociation of bicarbonate ions. Silicate species (blue in Figs. 2(b-d)) dissolved from cement particles respond to these local changes by polymerization reactions which prompt in-situ precipitation of silica skins around the particles as shown in Figs. 2(b-d). According to a recent study (Kellermeier et al. 2010), a high concentration of silica in fresh concrete can stabilize these calcium carbonate nanoparticles from aggregation. Due to the high affinity of this silica skin with calcium silicate hydrate (CSH), these calcium carbonate-silica nanoparticles provide ideal nucleation sites for the precipitation of CSH out of the pore solution. Figure 2(e) shows such nanoparticles found by scanning electron microscopy (SEM) in the precarbonated mortar sample after 5 days of hydration. It can be seen that most particles are around 100 $n m$. Energy-dispersive $\mathrm{x}$-Ray spectroscopy (EDX) element mapping on these particles shows that the major element is $\mathrm{Si}$ and no $\mathrm{C}$ can be detected, suggesting that these particles are truly covered by a silica skin. These nanoparticles and CSH precipitated on them fill the gap between cement particles. As a result, capillary porosity of the mortar is reduced (figure 2(f)), leading to a denser microstructure and higher compressive strengths.

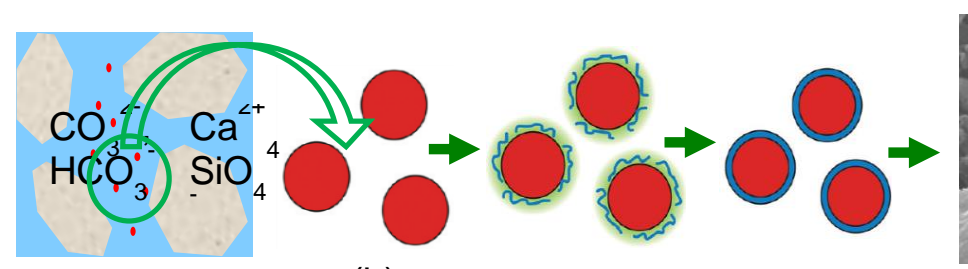

(a)

(b)

(c)

(d)

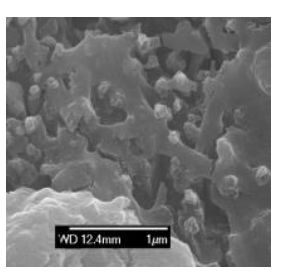

(e)

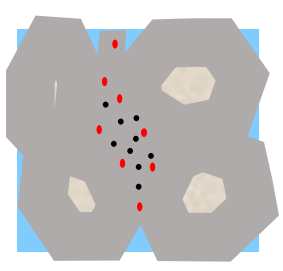

(f)

Figure 2. Mechanism of in-situ production of nanoparticles: (a-d); In basic environment of the fresh concrete, growing $\mathrm{CaCO}_{3}$ nanoparticles (red circles) generates $\mathrm{pH}$ gradientes (green) over their surfaces due to dissociation of bicarbonate ions. Silicate species (blue) respond to these local changes by polymerization reactions which prompt in-situ precipitation of silica skins around the particles; e) SEM images showing the produced nanoparticles in concrete; $f$ ) in-situ nanoparticles and their seeding effect to densify the microstructure of hardened concrete.

\section{EXPERIMENTAL INVESTIGATION}




\section{Specimen manufacturing}

2 " $\times 4$ " concrete (mortar) cylinder specimens were made using Sakrete ${ }^{\circledR}$ type I/II Portland cement, water, and standard graded fine aggregate at mass ratio of 920:500:2520. Three possible applications of the new technology were considered in the preliminary testing: 1) application with only OPC or non-reactive mineral fillers; 2) application with calcium rich SCMs such as high calcium fly ash; and 3) application with low or non-calcium SCMs such as metakaolin. In the first application, slaked lime manufactured by the Montevallo Plant (owned by Lhoist North America) was used to replace 1\% of OPC. The slaked lime slurry was first carbonated and then mixed with other ingredients to make cylinder specimens. To demonstrate the necessity of pre-carbonation, a group of specimens were also made using $1 \%$ slaked lime without pre-carbonation to replace OPC. Another group of specimens were made with $1 \%$ limestone powder to replace OPC to show the advantages of the pre-carbonation method over the method of directly adding limestone powders. In the second application, a control group of specimens were made with $20 \%$ of OPC replaced by high calcium fly ash. To make the precarbonated group, the high calcium fly ash slurry was quickly carbonated and then mixed with other ingredients to make specimens. In the third application, the control group was made with $20 \%$ OPC replaced by metakaolin. Since calcium content is very low in metakaolin, $1 \%$ (of OPC) slaked lime slurry was first carbonated and then mixed with metakaolin, OPC, and other ingredients to make the processed group.

\section{Characterization method}

Compressive strength and modulus of elasticity will be determined using $2 \times 4$ in. cylinders. SEM will be used to verify whether pre-carbonation can produce a denser microstructure in concrete. Isothermal calorimetry testing will be carried out to examine the effect of pre-carbonation on the early age hydration of cement. XRD analysis will be carried out to confirm that calcium carbonate can be produced by the pre-carbonation method.

\section{RESULTS AND DISCUSSIONS}

\section{Strength of the specimens}

The compressive strengths of these 2 " $\times 4$ " cylindrical specimens were measured at different ages and are presented in figure 2. Compared with the control group, adding pre-carbonated slaked lime can enhance the compressive strengths of the mortar at ages of 3, 7, and 28 days by $13 \%, 16 \%$, and $16 \%$, respectively. If only $1 \%$ OPC is replaced by slaked lime and no pre-carbonation processing is used, no significant increase of the compressive strength of the mortar can be induced (figure 2(a)), indicating that pre-carbonation is necessary to enhance the strength of the mortar. While replacing $1 \%$ of OPC with limestone powder can actually reduce the strength of the mortar, as shown in figure 2(a). Figure 2(b) shows that pre-carbonation can increase the compressive strength of the mortar made with $20 \%$ OPC replaced by high calcium fly ash at ages of 3, 7 and 56 days by $18 \%, 6 \%$, and $10 \%$, respectively. Similarly, pre-carbonation can improve the compressive strength of the mortar with $20 \%$ of OPC replaced by metakaolin at ages of 3, 7, and 28 days by $17 \%, 17 \%$, and $11 \%$, respectively, as shown in figure 2(c). Although this is our first trial, it already shows that the precarbonation method can significant enhance the strength of the mortar. If optimal pre-carbonation parameters are used, more improvement on strength may be achieved. 

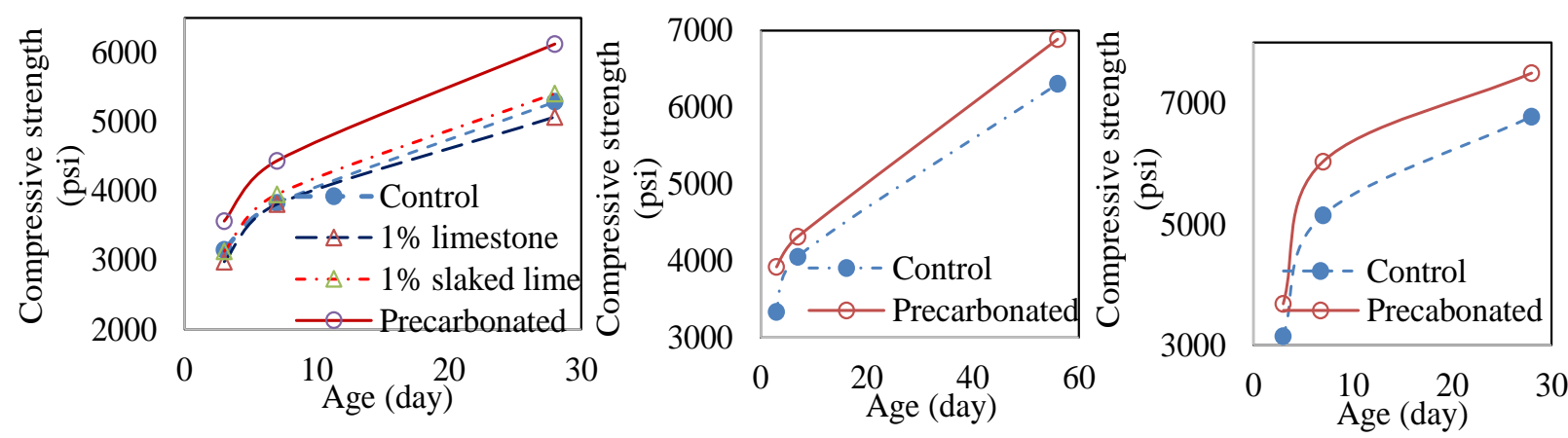

Figure 3. Strength enhanced by pre-carbonation: (a) 1\% replacement with slaked lime; (b) $\mathbf{2 0 \%}$ replacement with fly ash; c) $20 \%$ replacement with metakaolin.

\section{Microstructure of the specimen}

Figure 4(a) shows the representative microstructure of the pre-carbonated sample. A close-up of figure 4(a) showing $\mathrm{CaCO}_{3}$ nanoparticles with silica skin is shown in figure 4(b); figure 4(c) shows the possible calcite particles with size around $100 \mathrm{~nm}$ exposed after polishing the sample. Figure 5 shows two different phases of $\mathrm{CaCO}_{3}$ existing in the pre-carbonated mortar sample. Figure 5(a) shows a $\mathrm{CaCO}_{3}$ particles found in the pre-carbonated specimen at age of 7 days. Its spherical shape suggests that this is a vaterite particle, an unstable crystalline structure of calcium carbonate. Figure 5(b) shows another $\mathrm{CaCO}_{3}$ particle in the pre-carbonated mortar sample at age of 28 days. Its rhombohedron shape suggests this particle is a calcite. Figure 5 confirms that precarbonation does produce calcium carbonate particles in concrete and that phase transform of calcium carbonate can occur in pre-carbonated mortar too.
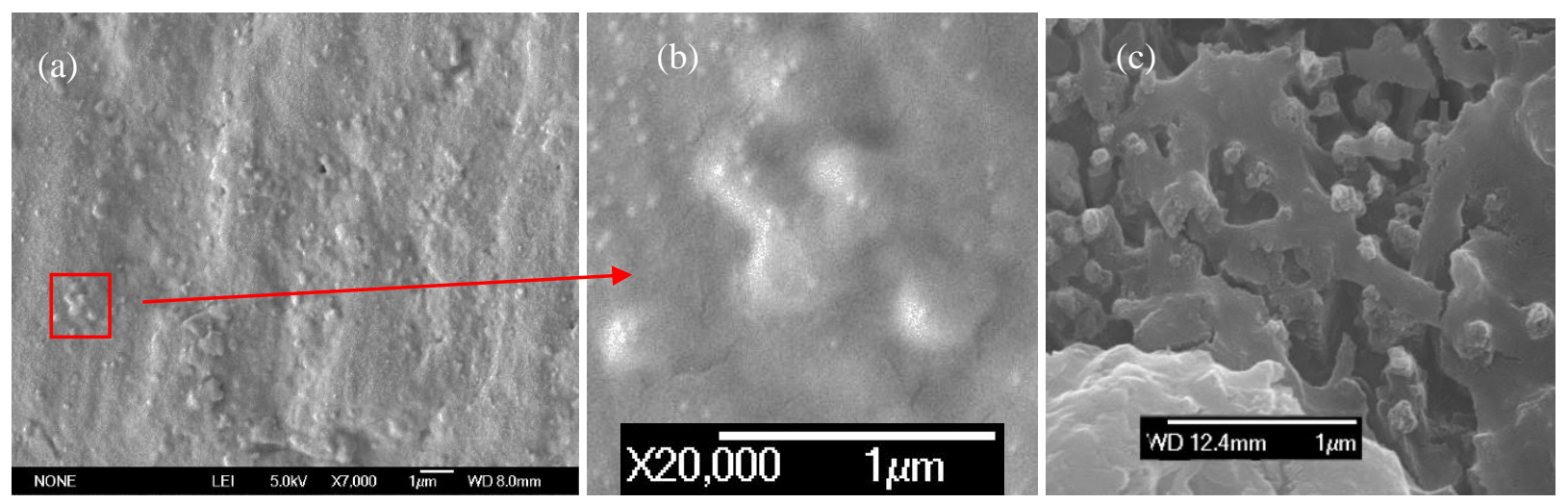

Figure 4. a) SEM image of precarbonated mortar specimen; (b) close-up of (a) showing CaCO3 nanoparticles with silica skin; (c) possible calcite particles with size around 100 nm exposed after polishing the sample.

\section{XRD analysis}

In order to verify that calcium carbonate can be produced in fresh concrete by pre-carbonation, fresh pre-carbonated cement mortar was diluted with water one hour after mixing and then filtered to remove unreacted cement particles and un-precipitated ions in the fresh mortar. The residual precipitant was then analyzed by XRD. The result is presented in figure 6 , which clearly shows that calcium carbonate has been produced in fresh cement mortar through pre-carbonation. 


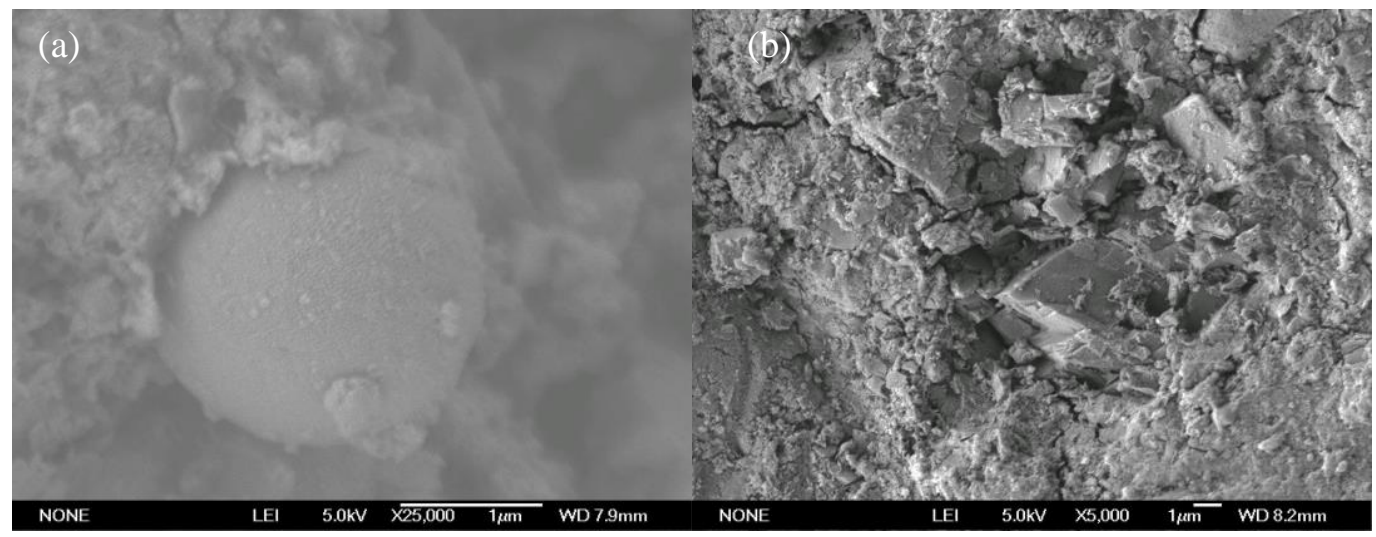

Figure 5. Calcium carbonate found in the pre-carbonated mortar sample:

(a) vaterite; (b) calcite

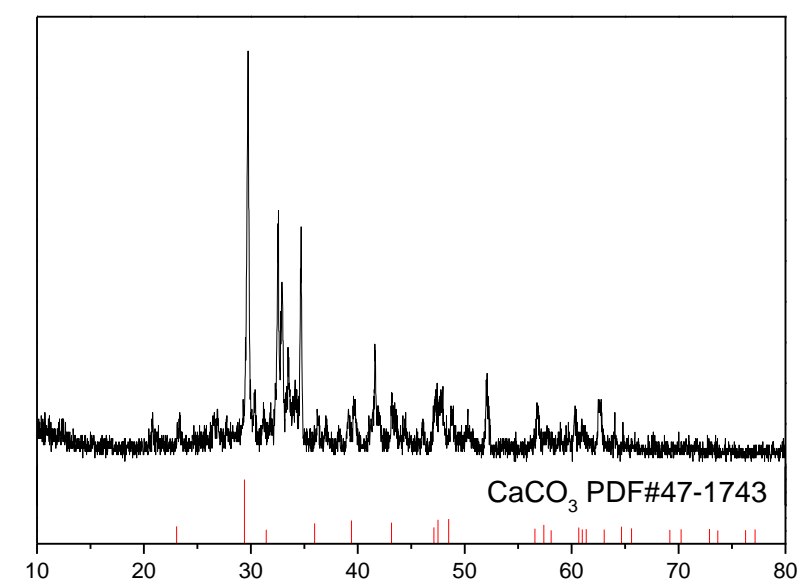

Figure 6. $\mathrm{CaCO}_{3}$ particles existing in fresh cement mortar revealed by XRD spectrum

\section{Isothermal calorimetry testing result}

\section{Calorimetry testing}

Isothermal calorimetry curves shown in figure 7(a). The close-up of the curves in the first hour of hydration (figure 7(a)) shows that the pre-carbonated sample has much higher heat flow than other three samples, suggesting that nanoparticles are mainly produced in this period. Because the formation of calcium carbonate consumes more $\mathrm{Ca}^{2+}$ and $\mathrm{OH}^{-}$in the fresh concrete, pre-carbonated sample has a longer dormant period than other samples, as shown in figure 7(a). Due to the formation of nanoparticles between cement particles, this longer dormant period doesn't lead to longer setting time or lower early age strength. The initial and final setting times of the pre-carbonated sample are 126 mins. and 185 mins., respectively; while the corresponding setting time of the control group are 135 mins. and 201 mins., respectively. It can be seen that pre-carbonation can slightly reduce the setting time, which is important for some mineral application in concrete. As shown in figure 3, this longer dormant period has no negative effect on the strength development of the concrete. The early age strength of pre-carbonated specimens measured at 3 and 7 days all show_significant improvement. Figure 7(b) shows that after overcoming the deficit of the longer dormant period due to in-situ production of nanoparticles, the accumulative energy released from the pre-carbonated sample exceeds other samples, suggesting that pre-carbonation can promote the hydration of the cement, which also contributes to higher strength of the processed mortars. 


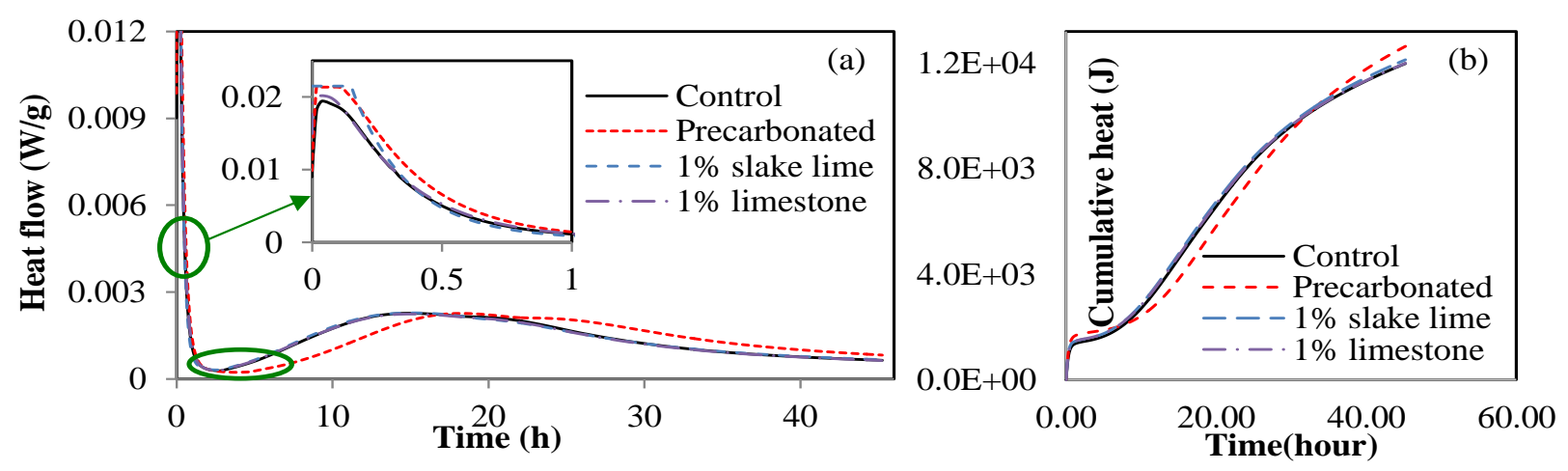

Figure 7. Isothermal calorimetry curves of cement pastes: (a) heat flow; (b) accumulative heat.

\section{CONCLUSION}

This research explores a novel manufacturing technique to enhance the sustainability of Ordinary Portland Cement (OPC) based concrete through using carbon dioxide $\left(\mathrm{CO}_{2}\right)$ as an admixture to induce in-situ production of nanoparticles in fresh concrete. In this technique, gaseous $\mathrm{CO}_{2}$ is first absorbed into slurry of calcium-rich minerals which are then blended with other ingredients to produce concrete. Pre-carbonation can produce in-situ nanoparticles in fresh concrete which provides ideal nucleating sites for hydration products of OPC and densifies the microstructure of the concrete. Significant strength enhancement can be achieved by this technology. More study is undergoing to understand the beneath mechanism of this method.

\section{ACKNOWLEDGEMENTS}

Support for this research project was provided by The University of Alabama and National Science Foundation through CMMI 1000580.

\section{REFERENCES}

Cheung J., Jeknavorian A., Roberts, L., and Silva D. (2011). "Impact of Admixtures on the Hydration Kinetics of Portland Cement." Cement and Concrete Research 41, 1289-1309.

De Weerdt, K., Ben Haha, M, Le Saout, G, Kjellsen, K., Justnes, H., and Lothenback, B. (2011). "Hydration Mechanisms of Ternary Portland Cement Containing Limestone Powder and Fly Ash." Cement and Concrete Research 41, 279-291.

Kachinski, J. (1983). "Method of Processing Waste Cement Kiln Dust to Make a Soil Treatment Composition." US Patent 4,402,891.

Kellermeier, M., Melero-Garcia, E., Glaab, F., Klein, R., Drechsler, M., Rachel, R., Manuel, J., Garcia-Ruiz, and Kunz, W. (2010). "Stabilization of Amorphous Calcium Carbonate in Inorganic Silica-Rich Environments." J Am. Chem. Soc. 132, 17859-17866.

Lothenbach, B., Le Saout, G., Gallucci, E., and Scrivener, K. (2008). "Influence of Limestone on the Hydration of Portland Cements." Cement and Concrete Research 38, 848-860.

Péra, J., Husson, S., and Guilhot, B., (1999). "Influence of Finely Ground Limestone on Cement Hydration." Cement and Concrete Composites 21, 99-105.

Sato, T., and Beaudoin, J. (2010). "Effect of Nano-Caco3 on Hydration of Cement Containing Supplementary Cementitious Materials.” Advances in Cement Research 23, 1-29. 